\title{
Analisis Resiko Kecelakaan Kerja di CV. Jati Jepara Furniture dengan Metode HIRARC (Hazard Identification Risk Assessment and Risk Control)
}

\author{
Lamhot Willy Afredo*, Uni Pratama Pebrina Br Tarigan \\ Jurusan Teknik Industri, Fakultas Teknologi dan Ilmu Komputer Universitas Prima Indonesia Jl. Sekip simpang Jl \\ Sikambing Medan, Indonesia
}

E-mail:*willy.afredo@gmail.com

\begin{abstract}
Abstrak
CV Super Jati Jepara Furniture adalah usaha yang bergerak di bidang produksi mebel, yang memiliki beberapa potensi bahaya dikarenakan masih manual. Berdasarkan permasalahan tersebut untuk mengendalikan atau menghilangkan resiko dengan progam kesehatan dan keselamatan kerja (K3) adalah menggunakan metode HIRARC (Hazard Identification Risk Assesment and Risk Control). Data yang dikumpulkan seperti proses kerja, kejadian kecelakaan dalam proses kerja, dokumentasi untuk mempelajari dokumen-dokumen perusahaan, buku-buku, laporan-laporan penelitan sejenis yang berhubungan. Hasil penelitian basic risck didapatkan tingkat kecelakaan yang ditetapkan dalam tiga kategori, yaitu kategori tertinggi dengan nilai 4 dan 5, kategori sedang dengan nilai 2 dan 3, dan kategori rendah dengan nilai 1. Pengendalian risiko yang diusulkan untuk nilai 4 dan 5 dikategorikan sebagai nilai tertinggi dengan resiko yang dapat mengganggu pernafasan, pendengaran, yaitu menggunakan masker dan earplug (sumbat telinga), untuk nilai 3 dan 2 dikategorikan sebagai level medium yang dapat mengakibatkan luka pada tangan dan kaki, sebaikanya pekerja menggunakan sarung tangan dan sepatu, untuk nilai 1 yang dikategorikan sebagai level terendah yang dapat mengakibatkan iritasi kulit pekerja melakukan pencucian tangan setelah proses packing selesai.
\end{abstract}

Kata kunci: HIRARC, Kecelakaan Kerja, K3

\section{PENDAHULUAN}

Industri saat ini sedang mengalami persaingan yang ketat, oleh karena itu penting bagi manajemen untuk melakukan evaluasi terhadap performa perusahaan dan perencanaan tujuan di masa mendatang, Keselamatan dan Kesehatan Kerja (K3) adalah salah satu syarat untuk memenangkan persaingan dikarenakan K3 merupakan hak asasi karyawan dan salah satu syarat untuk dapat meningkatkan hasil ataupun produktivitas pekerja.

CV. Super Jati Jepara furniture adalah usaha bergerak di bidang produksi mebel, yaitu pembuatan seperti pintu, lemari, kursi, dll. Pabrik mebel ini memiliki beberapa potensi bahaya dikarenakan perusahaan masih manual, tidak sedikit bahaya yang sering terjadi di pabrik mebel tersebut, yaitu tangan dan kaki tertimpa kayu, tangan terkena bor, abu dri kayu bisa mengganggu pernapasan dan bisa melukai mata sampai iritasi. Untuk mengidentifikasi , mengurangi, mengendalikan atau menghilangkan resiko yang terkait dengan program kesehatan dan keselamatan kerja (k3) adalah dengan menggunakan HIRARC (Hazard identification risk assessment and risk control).

Untuk mengidentifikasi , mengurangi, mengendalikan atau menghilangkan resiko resiko yang terkait dengan program kesehatan dan keselamatan kerja (k3) adalah dengan menggunakan HIRARC (Hazard identification risk assessment and risk control) adalah salah satu metode teknik identifikasi, analisis bahaya dan pengendalian resiko yang digunakan untuk meninjau proses atau operasi pada sebuah system secara sistematis. Dengan menggunakan Hazard Identification Risk Assessment Control (HIRAC), diharapkan dapat dilakukan usaha pencegahan terjadinya kecelakaan kerja yang terjadi di perusahaan dan menghindari serta menanggulangi resiko tersebut dengan cara yang tepat. Oleh karena itu untuk pembahasan ini saya menganalisis serta mengevaluasi lingkungan kerja.

\section{Tujuan Penelitian}

Adapun tujuan dan manfaat penelitian ini adalah :

1. Mengetahui tingkat keselamatan dan kesehatan kerja pada perusahaan Cv. Super Jati Jepara Furniture Medan

2. Menentukan upaya pencegahan Keselamatan dan Kesehatan Kerja pada karyawan perusahaan Cv. Super Jati Jepara Furniture Medan 


\section{BAHAN DAN METODE}

\section{Pengertian K3}

Keselamatan dan kesehatan kerja (K3) adalah upaya perlindungan yang ditujukan agar tenaga kerja dan orang lainnya di tempat kerja/perusahaan selalu dalam keadaan selamat dan sehat, serta agar setiap sumber produksi dapat digunakan secara aman dan efisien (Kepmenaker Nomor 463/MEN/1993). Berdasarkan Undang-undang Ketenagakerjaan No.13 Tahun 2003 pasal 87, bahwa setiap perusahaan wajib menerapkan sistem manajemen keselamatan dan kesehatan kerja yang terintegrasi dengan sistem manajemen perusahaan.

\section{Jenis-jenis Bahaya Dalam K3}

Jenis-jenis bahaya dalam K3 dibagi menjadi 3, yaitu:

a. Jenis Kimia :

Terhirupnya atau terjadinya kontak antara manusia dengan bahan kimia berbahaya

b. Jenis Fisika :

Temperatur udara yang terlalu panas maupun terlalu dingin, keadaan yang sangat bising. Keadaan udara yang tidak normal

c. Jenis Proyek/Pekerjaan :

Pencahayaan atau penerangan yang kurang, bahaya dari pengangkutan barang, bahaya yang ditimbulkan oleh peralatan.

\section{Teknik Identifikasi Bahaya}

Pemilihan teknik identifikasi bahaya dilakukan agar teknik yang terpilih adalah teknik yang sesuai untuk digunakan dalam menyelesaikan masalah yang terjadi. Berikut beberapa teknik identifikasi bahaya yang bersifat proaktif antara lain :

1. Daftar Periksa dan audit atau inspeksi K3

2. Analisi bahaya awal

3. HAZOPS (Hazard anda Operability Study)

4. Analisis Keselamatan Pekerjaan

5. HIRARC (Hazard Identification, Risk Assesment an Risk Control)

\section{HIRARC}

HIRARC merupakan suatu elemen pokok dalam sistem manajemen Keselamatan dan Kesehatan Kerja yang berkaitan dengan upaya pencegahan dan pengendalian bahaya.

HIRARC adalah suatu dasar dalam mengidentifikasi bahaya, menilainya kemungkinan dan mengatur kemungkinan memiliki maksud HIRARC yaitu seperti berikut :

1. Untuk mengidentifikasi semua aspek yang bisa mengakibatkan kerugian pada karyawan dan sebagainya (yang bahaya)

2. Untuk memperhitungkan besar kemungkinan kemungkinan yang membahayakan siapa pun di lingkungan kerja, dan

3. Untuk sangat mungkin entrepreneur berencana, mengenalkan dan memonitor aksi mencegah untuk meyakinkan kalau resiko itu cukup dikendalikan setiap waktu.

Dalam melakukan rencana aktivitas, HIRARC harus memerhatikan beberapa hal berikut ini :

1. Mana bahaya yang nampaknya jadi ancaman yang penting

2. Mana bahaya yang nampaknya jadi ancaman yang pentingMeyakinkan apakah pengendalian yang ada mencukupi, dan

3. Melakukan sebelumnya proses aksi perbaikan atau pencegahan.

Dalam melakukan sistem HIRARC diperlukan 4 langkah simpel dalam melakukan HIRARC, yakni :

1. mengklasifikasikan aktivitas kerja

2. mengidentifikasi bahaya

3. melakukan penilaian kemungkinan (analisis dan memprediksi kemungkinan dari setiap bahaya), mengkalkulasi atau menaksir peluang terjadinya, dan keparahan bahaya

4. mengambil keputusan apakah resiko ditolerir dan mengaplikasikan beberapa langkah kontrol (bila perlu). 


\section{Penilaian Resiko}

Risiko adalah kemungkinan terjadinya kerugian atau keuntungan. Juga, suatu takaran dari potensi kerugian yang mempertimbangkan besarnya kerugian dan kemungkinan terjadinya (Bird, 1996 dalam Wiwin, 2010:11). Pengertian risiko menurut AS/NZS 4360:2004 adalah sebagai peluang munculnya suatu kejadian yang dapat menimbulkan efek terhadap suatu objek. Risiko diukur berdasarkan nilai likelihood (kemungkinan munculnya sebuah peristiwa) dan concequence (dampak yang ditimbulkan oleh peristiwa tersebut). Risiko dapat dinilai secara kualitatif, semi-kualitatif atau kuantitatif.

\section{Jenis Penelitian}

Jenis penelitian yang digunakan dalam penelitian ini adalah Studi Kasus, yang dimana Studi kasus merupakan penggalian informasi mendalam melalui permasalahan yang ada di sekitar kita. Data atau informasi mengenai permasalahan menjadi hal penunjang dalam mencari solusi. Dalam hal pengumpulan data terdapat beberapa langkah-langkah, yaitu :

- Mencari akar permasalahan

- Mencari data sekunder

- Melakukan observasi lapangan atau data primer

Data Primer yang yang dikumpulkan dalam penelitian yaitu melalui survei lapangan untuk memperoleh kesehatan dan keselamatan pekerja, faktor-faktor penyebab terjadi kecelakaan kerja, dan memperbaiki hasil kerja selama operasi berlangsung.

\section{Lokasi dan Objek Penelitian}

Lokasi penelitian dilakukan di CV. Super Jati Jepara Furniture alamat jalan karangsari kecamatan medan polonia. Objek yang diamati dalam penelitian ini adalah kondisi bangunan tempat kerja, pekerja dan kondisi lingkungan di area Super Jati Jepara Furniture.

\section{Kerangka Konseptual Penelitian}

Kerangka konseptual penelitian untuk penelitian ini adalah sebagai berikut:

\begin{tabular}{|l|l|}
\hline Variabel Independen & \\
- Mematuhi Prosedur Kerja & Variabel Dependen \\
- Perlengkapan APD & Meminimalisir Resiko \\
- Pelaksanaan Prosedur K3 & Kecelakaan Kerja \\
\cline { 2 - 2 }
\end{tabular}

\section{Gambar 1. Kerangka Konseptual}

\section{HASIL DAN PEMBAHASAN \\ Pengumpulan Data}

Data yang di gunakaan dalam penelitian ini bersumber dari data primer. Data primer yaitu data yang diperoleh langsung dari sumbernya.Untuk memperoleh data ini menggunakan 2 cara:

1. Wawancara

Wawancara merupakan kegiatan pengumpulan data dengan melakukan tanya jawab langsung. Wawancara digunakan agar terkumpul data tentang proses kerja, hal yang berkaitan dengan proses kerja, kejadian kecelakaan dalam proses kerja dan pengecekan temuan hasil pengamatan lapangan.

\section{Dokumentasi}

Dokumentasi adalah metode pengumpulan data dengan menggunakan benda tertulis, dalam hal ini yaitu form HIRARC yang dimiliki oleh Super Jati Jepara Furniture Selain itu teknik pengumpulan ini dengan cara mempelajari dokumen-dokumen perusahaan, buku-buku, laporan laporan penilitan sejenis, serta sumber lain yang berhubungan dengan peneliti.

Tabel 1. Data Kecelakaan kerja (2018-2020)

\begin{tabular}{|c|l|l|l|l|}
\hline Tahun & $\begin{array}{c}\text { Waktu } \\
\text { Kejadian }\end{array}$ & \multicolumn{1}{c|}{ Nama } & \multicolumn{1}{|c|}{ Bagian } & \multicolumn{1}{c|}{ Jenis Kecelakaan Kerja } \\
\hline $\mathbf{2 0 1 8}$ & 11 Desember & Amrizal & Amplas A & Terkena cutter \\
\hline $\mathbf{2 0 1 9}$ & 14 Februari & Yogi & Carpenter & Jari tangan terkena tatah \\
\hline
\end{tabular}




\begin{tabular}{|c|c|c|c|c|}
\hline & 28 Februari & Abdul & Amplas A & Jari kaki tertimpa DS 08 \\
\hline & 13 Maret & Junison & Amplas B & $\begin{array}{l}\text { Amplas B Ibu jari kaki tertimpa } \\
\text { lambung samping bed }\end{array}$ \\
\hline & 1 April & Riduan & Finishing & Jari tangan terkena pisau \\
\hline & 22 Juni & Hendrik & Amplas A & $\begin{array}{l}\text { Jari tangan terkena konveyor } \\
\text { mesin sanding }\end{array}$ \\
\hline & 14 Agustus & Erwin & Amplas E & Jari tangan terkena tatah \\
\hline & 28 September & Muhamad soleh & Carpenter & Jari tangan terkena tatah \\
\hline & 11 Oktober & Fajrul & Amplas B & $\begin{array}{l}\text { Jari tangan terkena mesin tarik } \\
\text { (spindle) }\end{array}$ \\
\hline & 8 November & Dimas & Mekanik & Mata terkena geram \\
\hline \multirow{5}{*}{2020} & 10 januari & Ryan & Amplas E & Mata terkena alteco \\
\hline & 19 Maret & Angga & Amplas B & $\begin{array}{l}\text { Mata terkena serbuk amplas } \\
\text { kitir }\end{array}$ \\
\hline & 24 Juli & Suprayetno & Carpenter & $\begin{array}{l}\text { Carpenter Badan tersiram air } \\
\text { panas }\end{array}$ \\
\hline & 6 September & Leo & Mekanik & Tangan terkena obeng \\
\hline & 18 Desember & Bobby & Mekanik & $\begin{array}{l}\text { Jari tangan terkena gerinda } \\
\text { mesin tangan }\end{array}$ \\
\hline
\end{tabular}

Pertanyaan berikutnya adalah untuk mengetahui pengetahuan mereka mengenai job safety analysis (JSA) dan sudah belumnya perusahaan menerapkan, semua dari pekerja tidak mengetahui apa itu JSA dan perusahaan belum mensosialisasikannya. setelah dijelaskan mengenai apa itu JSA, pekerja menjawab perlu diterapkan agar tidak banyak terjadi kecelakaan kerja lagi, agar mengerti penggunaan peralatan untuk menghindari bahaya, serta agar aman dan nyaman.

Tabel 2. Skala Tingkat Kemungkinan

\begin{tabular}{|c|l|l|}
\hline Tingkat & \multicolumn{1}{|c|}{ Deskripsi } & \multicolumn{1}{c|}{ Keterangan } \\
\hline 1 & Rare & Hampir tidak pernah terjadi \\
\hline 2 & Unlikely & Jarang terjadi \\
\hline 3 & Possible & Dapat terjadi sekali-sekali \\
\hline 4 & Likely & sering terjadi \\
\hline 5 & Almost Certaint & Dapat terjadi setiap saat \\
\hline
\end{tabular}

Tabel 3. Skala Tingkat Keparahan

\begin{tabular}{|c|l|l|}
\hline Tingkat & \multicolumn{1}{|c|}{ Deskripsi } & \multicolumn{1}{c|}{ Keterangan } \\
\hline 1 & Negligible & Tidak terjadi cidera, kerugian finansial sedikit \\
\hline 2 & Minor & Cidera ringan, kerugian finansial sedikit \\
\hline 3 & Moderate & idera sedang, perlu penanganan medis, kerugian finansial besar \\
\hline 4 & Major & Cidera berat $>$ 1 orang, kerugian besar, gangguan produksi \\
\hline 5 & Catastrophic & $\begin{array}{l}\text { Fatal > 1 orang, kerugian sangat besar dan dampak sangat luas, } \\
\text { terhentinya seluruh kergiatan }\end{array}$ \\
\hline
\end{tabular}

Tabel 4. Skala Tingkat Risiko

\begin{tabular}{|c|c|c|c|c|c|}
\hline \multirow{2}{*}{$\begin{array}{c}\text { Tingkat } \\
\text { Kemungkinan }\end{array}$} & $\mathbf{1}$ & $\mathbf{2}$ & $\mathbf{3}$ & $\mathbf{4}$ & $\mathbf{5}$ \\
\cline { 2 - 6 } & $\mathrm{L}$ & $\mathrm{L}$ & $\mathrm{L}$ & $\mathrm{L}$ & $\mathrm{M}$ \\
\hline $\mathbf{1}$ & $\mathrm{L}$ & $\mathrm{L}$ & $\mathrm{M}$ & $\mathrm{M}$ & $\mathrm{H}$ \\
\hline $\mathbf{2}$ & $\mathrm{L}$ & $\mathrm{M}$ & $\mathrm{M}$ & $\mathrm{H}$ & $\mathrm{H}$ \\
\hline $\mathbf{4}$ & $\mathrm{L}$ & $\mathrm{M}$ & $\mathrm{H}$ & $\mathrm{H}$ & $\mathrm{VH}$ \\
\hline $\mathbf{5}$ & $\mathrm{M}$ & $\mathrm{H}$ & $\mathrm{H}$ & $\mathrm{VH}$ & $\mathrm{VH}$ \\
\hline
\end{tabular}

Tabel 5. Kategori Tingkat Risiko 


\begin{tabular}{|c|l|l|}
\hline Simbol Huruf & \multicolumn{1}{|c|}{ Deskripsi } & \multicolumn{1}{|c|}{ Tindakan } \\
\hline L & Low Risk (tingkat bahaya rendah) & $\begin{array}{l}\text { Pemantauan untuk memastikan } \\
\text { tindakan pengendalian telah } \\
\text { berjalan dengan baik }\end{array}$ \\
\hline $\mathrm{M}$ & Moderate (tingkat bahaya sedang) & $\begin{array}{l}\text { memerlukan perhatian dan } \\
\text { tambahan prosedur }\end{array}$ \\
\hline $\mathrm{H}$ & $\begin{array}{l}\text { High Risk (tingkat bahaya } \\
\text { tinggi/serius) }\end{array}$ & $\begin{array}{l}\text { Penting mendapatkan perhatian } \\
\text { dari pihak Manajemen dan } \\
\text { tindakan memperbaiki }\end{array}$ \\
\hline $\mathrm{VH}$ & $\begin{array}{l}\text { Very High (tingkat bahaya sangat } \\
\text { tinggi) }\end{array}$ & $\begin{array}{l}\text { Perlu segera dilakukan tindakan } \\
\text { perbaikan }\end{array}$ \\
\hline
\end{tabular}

Penilaian risiko dilakukan dengan cara melakukan penyebaran kuesioner kepada pekerja dan pemilik perusahan salah satu pabrik mebel yang ada di CV. Jati Jepara Furniture alamat Jalan Karangsari Kecamatan Medan Polonia. Total responden berjumlah 4 orang, Masing-masing responden melakukan penilaian tingkat kemungkinan dan tingkat keparahan dari masing-masing potensi bahaya yang telah diidentifikasi pada tahapan sebelumnya.

\section{HASIL DAN PEMBAHASAN}

Berikut ini adalah hasil perhitungan skor yang sudah di dapat berdasarkan analisis risiko kecelakaan kerja secara semi kuantitatif.

Tabel 6. Hasil dan Pembahasan

\begin{tabular}{|c|c|c|c|c|c|c|}
\hline & \multirow[b]{2}{*}{ Tahap pekerjaan } & \multirow[b]{2}{*}{ Risiko } & \multirow[b]{2}{*}{ Akibat } & \multicolumn{2}{|c|}{ Tingkat } & \multirow[b]{2}{*}{$\begin{array}{c}\text { Tingkat } \\
\text { Risiko }\end{array}$} \\
\hline & & & & $\begin{array}{c}\text { Kemung } \\
\text { kinan }\end{array}$ & $\begin{array}{l}\text { Kese- } \\
\text { riusan }\end{array}$ & \\
\hline \multicolumn{7}{|c|}{ A. Kedatangan bahan mentah } \\
\hline \multirow{2}{*}{1} & \multirow{2}{*}{$\begin{array}{l}\text { Pengangkutan Bahan } \\
\text { baku dari kontainer } \\
\text { ke area Quality } \\
\text { Control }\end{array}$} & Tangan terluka & Cidara & 3 & 3 & $\mathrm{~L}$ \\
\hline & & Kaki terluka & Cidera & 2 & 3 & $\mathrm{~L}$ \\
\hline \multirow{5}{*}{2} & \multirow{5}{*}{$\begin{array}{l}\text { Pengangkutan } \\
\text { bahan baku dari area } \\
\text { Quality Control ke } \\
\text { gudang }\end{array}$} & Tangan terluka & Cidera & 4 & 2 & $\mathrm{~L}$ \\
\hline & & $\begin{array}{l}\text { Debu yang mengganggu } \\
\text { pernafasan }\end{array}$ & $\begin{array}{l}\text { Gangguan } \\
\text { pernapasan }\end{array}$ & 3 & 3 & $\mathrm{~L}$ \\
\hline & & Kaki dan tangan terluka & Cidera & 4 & 2 & $\mathrm{~L}$ \\
\hline & & Debu yang mengenai mata & iritasi & 4 & 2 & $\mathrm{~L}$ \\
\hline & & Jatuh dari lantai dua & Cidera/ cacat & 1 & 5 & VH \\
\hline \multicolumn{7}{|c|}{ B. Tukang / pengolahan awal } \\
\hline \multirow{4}{*}{1} & \multirow{4}{*}{$\begin{array}{l}\text { Memotong mebel } \\
\text { yang kurang pas } \\
\text { Ukurannya }\end{array}$} & $\begin{array}{lll}\begin{array}{l}\text { Tangan terkena alat } \\
\text { pemotong }\end{array} & \\
\end{array}$ & Luka & 3 & 3 & M \\
\hline & & $\begin{array}{cc}\text { Suara } & \text { gerinda } \\
\text { mengganggu pendengaran }\end{array}$ & $\begin{array}{l}\text { Gangguan } \\
\text { pendengaran }\end{array}$ & 3 & 4 & VH \\
\hline & & $\begin{array}{l}\text { Serbuk kayu yang } \\
\text { berterbangan mengganggu } \\
\text { pernafasan }\end{array}$ & $\begin{array}{l}\text { Gangguan } \\
\text { pernapasan }\end{array}$ & 3 & 4 & VH \\
\hline & & Kaki tertimpa mebel & Memar & 2 & 3 & $\mathrm{M}$ \\
\hline \multirow{2}{*}{2} & \multirow[b]{2}{*}{$\begin{array}{l}\text { Menyetel pintu } \\
\text { lemari, pintu laci }\end{array}$} & Tangan terkena palu & Memar & 3 & 2 & $\mathrm{M}$ \\
\hline & & $\begin{array}{l}\text { Tangan terkena tatah / } \\
\text { pahat }\end{array}$ & Memar & 2 & 3 & M \\
\hline
\end{tabular}




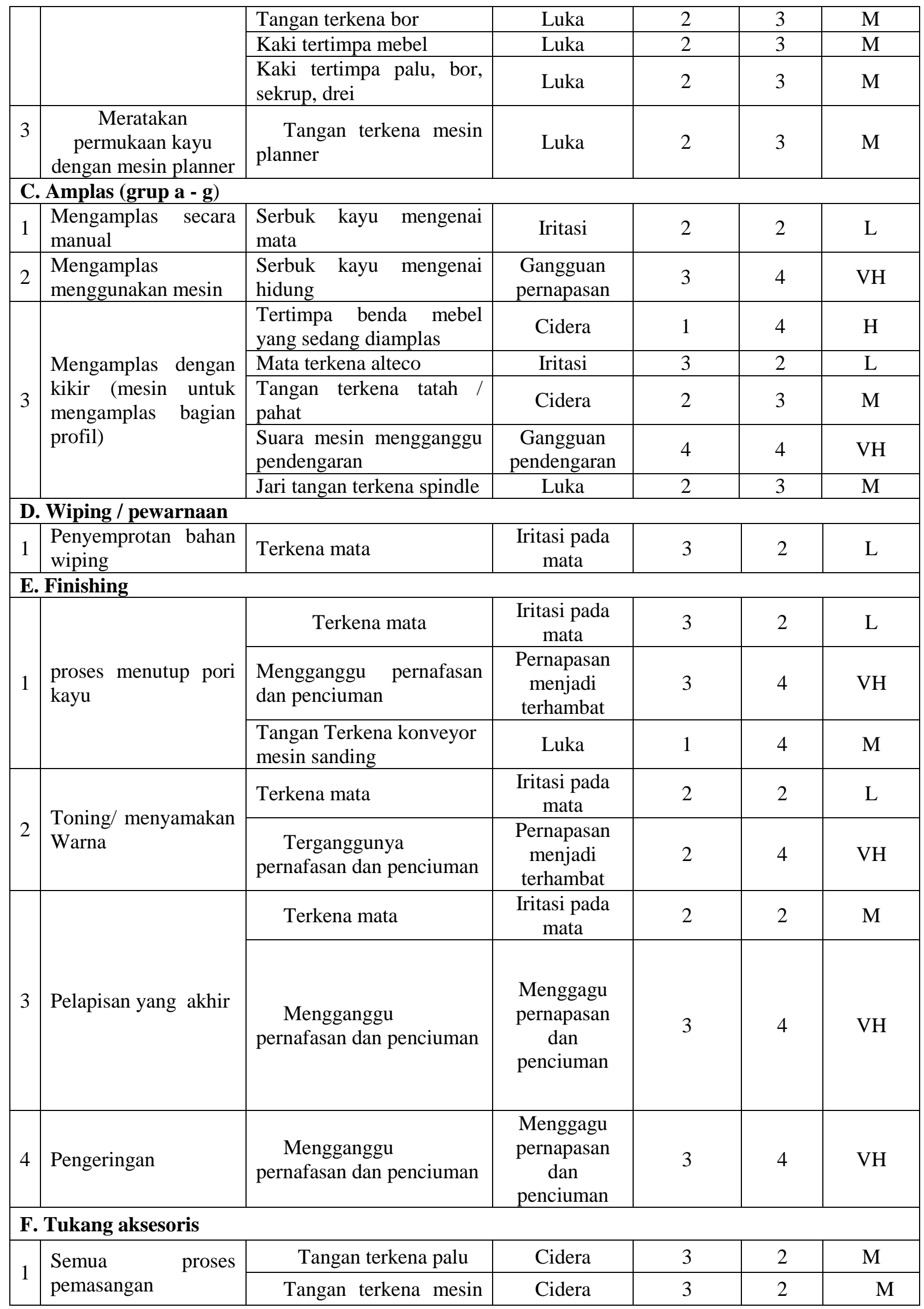




\begin{tabular}{|c|c|c|c|c|c|c|}
\hline & $\begin{array}{lr}\text { aksesoris } & \text { (memasang } \\
\text { engsel, } & \text { memasang } \\
\text { handle } & \text { pintu, } \\
\text { memasang } & \text { kaca, } \\
\text { memasang } & \text { busa dan } \\
\text { kain kursi) } & \\
\end{array}$ & bor & & & & \\
\hline \multicolumn{7}{|c|}{ G. Touch up } \\
\hline 1 & $\begin{array}{l}\text { Pengecekan tahap } \\
\text { akhir (menguatkan, } \\
\text { pmembersihkan) }\end{array}$ & Tangan terkena palu & Memar & 3 & 2 & M \\
\hline \multicolumn{7}{|c|}{ H. Packing } \\
\hline 1 & Memotong karton & Tangan terkena cutter & Luka & 4 & 2 & $\mathrm{~L}$ \\
\hline 2 & Perakitan karton & $\begin{array}{l}\text { Tangan terkena } \\
\text { lem/pelekat }\end{array}$ & Iritasi kulit & 5 & 1 & $\mathrm{~L}$ \\
\hline
\end{tabular}

Terlihat dari tabel tersebut telah ditetapkan skor dari masing-masing potensi risiko yang dapat terjadi. faktorfaktor yang ada disekitar harus mempertimbangkan penilaian faktor-faktor yang ada disekitar dan peneliti tetap mempertimbangkan faktor-faktor yang ada di sekitar. Risiko yang dapat diterima yaitu tangan terkena permukaan mebel yang masih kasar, tangan terkena pemotong, dan tangan terkena palu, bor, drei, sekrup, lem. Kemudian yang termasuk risiko rendah adalah kaki terkena mebel, tangan terkena pahat, serbuk kayu mengenai mata, tertimpa mebel yang sedang diamplas, mata terkena alteco, dan bahan finishing terkena mata. Kemudian yang termasuk risiko medium adalah tangan terkena mesin planner, maju masuk ke mesin planner, jari terkena spindle, terkena konveyor mesin sanding, dan tangan terkena cutter. selanjutnya risiko tinggi seperti debu, jatuh dari lantai dua, serbuk kayu mengenai mata, suara gerinda dan mesin-mesin mengganggu pendengaran serta aroma bahan finishing yang bisa mengganggu pernafasan. Berikut adalah tabel hasil dari data kecelakaan kerja yang tinggi ke rendah.

Tabel 7. Data kecelakaan

\begin{tabular}{|l|l|l|}
\hline \multicolumn{2}{|c|}{ Nilai tertinggi (4 \& 5) } & \multicolumn{2}{|c|}{ Nilai medium (3 \& 2) } & \multicolumn{1}{|c|}{ Nilai terendah (1) } \\
\hline Nilai tertinggi dalam & Level medium yaitu & Kemudian level terendah dengan \\
proses penilaian tersebut & dengan nilai berkisar 3 \& & nilai 1 yaitu tangan terkena lem. \\
adalah 4 \& 5 seperti debu & 2 Yang termasuk dalam & \\
dan serbuk kayu yang & level medium adalah & \\
mengganggu pernafasan & seperti tangan terkena & \\
dan cairan penyemprot & mesin planner, jari tangan & \\
finishing yang & terkena spindle, terkena & \\
mengganggu penciuman & konveyor mesin sanding,. & \\
dan jatuh dari lantai 2 serta & & \\
suara mesin yang & & \\
mengganggu pendengaran. & & \\
\hline
\end{tabular}

Potensi bahaya pada CV. Super Jati Jepara dalam memproduksi mebel, dengan kategori nilai tertinggi dalam proses penilaian tersebut adalah 4 dan 5 seperti debu dan serbuk kayu yang dapat mengganggu pernafasan, penciuman dan pendengaran, pekerjaan dengan tingkat resiko tinggi berada pada kegiatan pengangkutan bahan baku, pemotongan mebel, pengamplasan kayu, proses pengecatan, proses pengeringan maka disarankan pekerja untuk menggunakan masker dan earplug (sumbat telinga).

Untuk kategori nilai medium dalam proses penilaian tersebut adalahh 3 dan 2 seperti dapat mengakibatkan luka pada kaki dan tangan, terkena alat pemotong, terkena palu, tangan terkena mesin planer, pekerjaan dengan tingkat resiko medium berada pada kegiatan pemotongan mebel kayu, penyetelan pntu lemari dan pintu laci, pengamplasan secara manual dan secara otomatis, maka disarankan pekerja untuk menggunakan sepatu boot dan sarung tangan. 
Kemudian kategori level terendah dalam proses penilaian tesebut adalah 1 yang dapat mengakibatkan iritasi kulit, pekerjaan dengan nilai resiko terendah berada pada kegiatan perakitan karton atau proses packing, maka dsarankan pekerja untuk menggunakan sarung tangan.

\section{KESIMPULAN}

Berdasarkan hasil dan pembahasan maka dapat disimpulkan bahwa: Bahaya yang terdapat di CV Super Jati Jepara Furniture yaitu berupa nilai tertinggi dalam proses penilaian tersebut adalah $4 \& 5$ seperti debu dan serbuk kayu yang mengganggu pernafasan dan cairan penyemprot finishing yang mengganggu penciuman dan jatuh dari lantai 2 serta suara mesin yang mengganggu pendengaran, memiliki nilai yang begitu tinggi karena efek jangka panjangnya akan mempengaruhi kesehatan pekerja dan berkelanjutan terus-menerus. Level medium yaitu dengan nilai berkisar 3 \& 2 Yang termasuk dalam level medium adalah seperti tangan terkena mesin planner, jari tangan terkena spindle, terkena konveyor mesin sanding, dan tangan terkena cutter. Kemudian level terendah dengan nilai 1 yaitu tangan terkena cutter dan tangan terkena lem pada saat pengepakan/packing.

\section{DAFTAR PUSTAKA}

[1] Nining, W, 2018. Pengaruh kesehatan dan keselamatan kerja (k3) Terhadap karyawan pada PT.Kutai Tambai.

[2] Dian P, R., Resti P., Dyan S, 2015. Analisis kecelakaan kerja dengan menggunakan metode Hazard on Operability (HAZOP).

[3] Supriadi, A, N., Abu Rizal, 2015. Identifikasi Bahaya dan Penilaian Resiko K3 pada tindakan Perawatan \& Perbaikan Menggunakan METODE HIRARC (Hazard Identification and risk assessment risk Control) pada PT. X.

[4] Indragiri, S, 2018. Manajamen Resiko K3 menggunakan Hazard Identification Risk assessment and Risk Control (HIRARC).

[5] Robi, A, R., Rimantho, D, 2016. Strategi Pengelolaan K3 Proyek Pemasangan Pipa Gas Menggunakan Pendekatan Metode AHP

[6] Hariyono, W., Yusuf, F, A, 2016. Aspek Keselamatan dan Kesehatan Kerja (K3) di Unit Sarana PT. Kereta Api Indonesia (Persero) Daerah Operasi VI Yogyakarta

[7] Susi, N., Indah, S, 2019. Analisis Risiko K3 dengan menggunakan Hazard Identification Risk assessment and Risk Control (HIRARC).

[8] Rosita, R, A., Dino, R, 2018. Gambar Penentuan Prioritas Strategi Pengelolaan K3 Proyek Pemasangan Pipa Gas Menggunakan Pendekatan Metode AHP

[9] Irfan, M., Indri, H, S, 2021. Analisa manajament resiko K3 Dalam Industri Manufaktur di Indonesia : Literature

[10] Suparjo., Risky, Y, 2021. Keselamatan dan Kesehatan Kerja (K3) di PT. ABC dengan pendekatan metode Fishbone Diagram

[11] Lina, D, F., Wardana R. M., Nadine A, G, 2019. Analisis Risiko k3 dengan menggunakan metode Hazard Identification Risk assessment and Risk Control (HIRARC). Pada industri Tahu dan Tempe Kelurahan Selili, Samarinda.

[12] Sofian, B, 2020. Analisis Tingkat Resiko Bahaya K3 pada Pengelolaan Apartemen menggunaan Hazard Operability study (HAZOPS)

[13] Hutagalung, O, A., Zulfa, F, I, 2018. Pengaruh keselamatan dan kesehatan kerja dan disiplin kerja terhadap kinerja kerja karyawan cleaning servise Pt. X di Jakarta

[14] Rudy, D., Nurul U, 2017. Identifikasi Bahaya Resiko kecelakaan kerja dengan Metode Hazard Identification Risk assessment ( HIRA ) di area Batching Plant PT XYZ

[15] Sony, H., Ambar, S, 2017. Analisa Tentang Pelaksana Program Keselamatan dan Kesehatan Kerja (K3) karyawan PT. Universal Jasa Kemas. 